\title{
PERCEIVED SOCIAL STIGMATIZATION AND COPING STRATEGIES AS PREDICTORS OF PSYCHOLOGICAL WELL- BEING AMONG FEMALE PARTNERS OF PRISONERS
}

\author{
Bada Bukola Victoria, Balogun Shyngle Kolawole and Adejuwon Grace Anuoluwapo
}

Department of Psychology, University of Ibadan, Nigeria

Received 2014-02-19; Revised 2014-03-17; Accepted 2014-04-02

\begin{abstract}
The objective of this study is to examine how coping strategies and perceived social stigmatization predicts the psychological wellbeing of female partners of prisoners in Ibadan, Nigeria. Using the purposive sampling techniques, a total of one hundred and nine (109) female partners of prisoners in Ibadan participated in the study. The ages of the participants ranged between 20 years to 65 years. Data collection was through the use of questionnaires. $2 \times 2 \times 2$ ANOVA and T-test was used to test the hypothesis. Findings indicates that coping strategies (problem focused and emotion focused) and perceived social stigmatization jointly predicted psychological well-being with $(\mathrm{F}(1,101)=13.50$; $\mathrm{p}<0.001)$. Also there was significant difference between the psychological wellbeing of partners with low $(\mathrm{X}=72.76, \mathrm{SD}=10.28)$ perceived social stigmatization and High $(\times=66.39, \mathrm{SD}=7.37)$ perceived social stigmatization, $(\mathrm{t}=3.65 ; \mathrm{df}=107 ; \mathrm{p}<0.05)$.
\end{abstract}

Keywords: Coping Strategies, Perceived Social Stigmatization, Psychological Wellbeing

\section{INTRODUCTION}

The negative effects that imprisonment has on the psychological well-being the female partners of the incarcerated are a reason for concern in Nigeria and around the world. It has been observed in the literature that psychological wellbeing, especially of those going through a stressful life event, such as the prisoners' spouses, is the focus of intense research attention (Diener et al., 1995). A woman who becomes a prisoner's wife has to deal with major changes in her lifestyle; she often must cope with totally new situations, such as establishing new social relationships, raising the children alone, as an individual rather than as a single parent. Understanding how women deal with the stress of their husbands' imprisonment, the types of problems that they and their families encounter and the resources they draw upon can provide an insight into the overall position of women in modern society (especially in Nigeria) and shed light on this neglected area of study (Bada et al., 2013; 2014; Grinstead et al., 2001). From the sparse literature on prisoners' families, it is yet unclear what mode of coping wives employ in response to their husbands' imprisonment and how they deal with the perceived stigmatization encountered as result of the situation.

When a partner is taken into custody, the wife may be subject to stressors that impinge on her wellbeing. Psychological wellbeing resides within the experience of the individual (Campbell, 1976). According to Diener et al. (1995), psychological wellbeing is said to be a person's evaluation reaction (the way an individual reacts to the judgement of the presenting situation, positively or negatively/favourably or unfavourably) to their life either in terms of life satisfaction (cognitive evaluations) or affects (ongoing emotional reaction). One way to think about psychological wellbeing is by looking at how effectively and successfully a person functions, feels capable and competent; is able to handle normal level of stress; maintains satisfying Corresponding Author: Bada Bukola Victoria Balogun, Department of Psychology, University of Ibadan, Nigeria 
relationships; and is able to bounce back or recover from difficult situations (Diener et al., 1995). Psychological wellbeing has been found to correlate positively with a variety of indicators of psychological adjustment and overall wellness. For example, social adjustment, possession of strong coping skills and resiliency in times of stress and personal crises have all been linked to higher level of psychological wellbeing (Wolf and Stevens, 2001; Kamya, 2000).

One of the factors that could affect the psychological wellbeing of female partners of prisoners is perceived social stigmatization. Social stigma has been defined as a mark or flaw resulting from personal or physical characteristics that are viewed as socially unacceptable (Blaine, 2010). The stigma associated with being a partner or relative of a prisoner therefore is the perception that a person who has family ties with a prisoner is undesirable or socially unacceptable (Vogel et al., 2006). For example, it has been reported that women take up the status of the imprisoned husbands and that the public often describes relatives of prisoners in negative terms (Angermeyer and Dietrich, 2006). For example, survey research has shown that the majority of community respondents report negative attitudes toward people with an identified family member in prison (Crisp et al., 2000). The stigma attached to being a prisoner may not be the same as the stigma associated with being the partner of a prisoner: Researchers have found that people tend to report more stigma surrounding partners or relatives of prisoners than around prisoners themselves (e.g., Corrigan and Matthew, 2003). Given the negative perception to relatives of prisoners, it is not surprising that individuals hide their family ties with incarcerated individuals so as to avoid being labeled and stigmatized (Corrigan and Matthew, 2003). Adegoke (2011) also reported that friends and family members of incarcerated persons are often victims of social stigmatization by members of the public and according to Adegoke (2011), there is a general negative perception of families who have relatives in prison; this therefore may put a strain, (stressor) on their psychological wellbeing. It is therefore pertinent to address this problem by investigating the effect of social stigmatization empirically on the psychological wellbeing of partners (in this case female partners) of prisoners.

Another factor that can mediate on the psychological wellbeing of the female partners of prisoners, even in the face of social stigmatization, is the coping strategies adopted by them. The wife who is not incarcerated may be depressed, disorientated and feel unable to cope with the situation, which can have a negative result on her psychological wellbeing. Aungles (1994) wrote that a common finding in reports on families of prisoners is that women (wives) are at risk of stress and physical illness when they suddenly find themselves taking on the role of household head in the absence of their husbands while in prison. When a person is mentally well, stressors do not have as significant an effect on them. While there is no way to eliminate all stressors, being psychologically well makes it easier for people to cope with and determine how to solve problems that arise.

One of the factors expected that could reduce the effect of incarceration on psychological wellbeing of female partners of prisoners is the coping strategies utilized by the individuals. Coping has been defined as "a specific effort by which an individual attempts to reduce or manage a demand on the family system" (Carlson and Cervera, 1992). The most widely used definition of coping is that offered by Lazarus and Folkman (1984), who stated it as the "constantly changing cognitive and behavioural efforts to manage specific external or internal demands that are appraised as taxing or exceeding the resources of the person". Coping helps an individual to confront the reality that they are responsible for their own state of psychological wellbeing. The idea that coping strategies can have positive functions parallels recent research, highlighting the role of coping in the promotion of health (Taylor et al., 2000). There are different reasons why people believe that coping might contribute to the promotion of psychological wellbeing. For example, coping may predict to higher levels of physical health by promoting better health practices. Also, individuals who have well-developed psychological resources, including a sense of personal coping and optimism, are more likely to cope with respect to health, which may minimize the effects of stress (Aspinwall and Taylor, 1997).

Life generally is stressful; without good coping skills, an individual may experience poor psychological wellbeing. Stress is the combination of psychological, physiological and behavioural reactions that people have in response to events that threaten or challenge them. After a stressor has been appraised, the next step is coping. How well people are able to cope with stressors influences the extent to which stress responses follow them. Coping strategies can be divided into two broad categories: Problem-focused coping and emotionfocused coping (Lazarus and Folkman; 1984; Perlin and Schooler, 1978). Problem-focused coping involves trying to manage or alter stressors, while emotion-focused 
coping involves trying to regulate the emotional responses to stressors. Although people tend to use both forms of coping in most cases Folkman and Lazarus (1980), the relative use of each of these forms of coping largely depends on the context. Problem-focused coping is more appropriate for problems in which a constructive solution can be found, such as family-related or workrelated problems. Alternatively, emotion-focused coping is more appropriate for problems that just have to be accepted, such as physical health problems (Vitaliano et al., 1990).

According to Folkman et al. (1986a; 1986b), problem-focused coping strategies include the following three types:

- Confronting, which means changing a stressful situation assertively, for example, "I stood my ground and fought for what I wanted

- Seeking social support, which means obtaining emotional comfort and information from other people, for example, "I talked to someone to find out more about the situation

- Planful problem solving, which means solving a stressful problem through deliberate problemfocused strategies, for example, "I made a plan of action and followed it

Emotion-focused coping strategies, in contrast, include the following five types:

- Self-controlling, which means regulating one's feelings, for example, "I tried to keep my feelings to myself

- Distancing, which means detaching oneself from a stressful situation, for example, "I didn't let it get to me; I tried not to think about it too much

- Positively reappraising, which means finding positive meaning in a stressful experience by focusing on personal growth, for example, "I changed my mind about myself

- Accepting responsibility, which means acknowledging one's role in a stressful problem, for example, "I realized I brought the problem on myself

- Escaping/Avoiding, which means wishful thinking or escaping or avoiding a stressful situation by way of activities like eating, drinking, or using alcohol or other drugs, for example, "I wished that the situation would go away or somehow be over with

Some researchers have referred to factors that seem particularly important in determining successful adjustments which include effective coping (Claerhout et al., 1982; Launius and Jensen, 1987) and perceived control (Cantos et al., 1993; Miller and Porter, 1983; Oevrholser and Moll, 1990). Problem solving and emotion-focused coping are the terms used by Compas (1987) and Lazarus and Folkman (1984), who have found problem-solving to be utilized in order to change situations while altering situations themselves elicit emotion-focused coping. Studies have indicated that emotion-focused coping strategies afford better adjustment when one faces uncontrollable stressors (Cairns and Wilson, 1989). In contrast, problem-focused coping strategies may be more effective in decreasing psychological distress when dealing with high-control stressors (Conway and Terry, 1992; Cooper and Payne, 1991; Goldberg and Breznitz, 1982; Lazarus, 1993; Whatley et al., 1998). It could be inferred from the reviewed literature above that the coping strategies adopted by the female partners of prisoners may have a significant effect on their psychological wellbeing.

The body of research conducted on spouses of incarcerated men, especially within the Nigerian context, is very limited. The far-reaching effects or influence of imprisonment on these secondary victims, especially their psychological wellbeing, needs be investigated towards developing a policy that would take care of the spouses and family left behind. Several studies on incarceration in Nigeria have been directed at issues affecting prison inmates while in custody (Atere, 2000; Odekunle, 1976). Not much is known about the implication of incarceration for the psychological wellbeing of prisoners' partners, which is the focus of the present study (in this case, female partners). Though Bada et al. (2013; 2014) examined the psychological factors predicting psychological wellbeing among spouses of incarcerated males, the current study differs in that it addresses factors such as coping strategies and perceived social stigmatization that can equally affect psychological wellbeing were examined.

Therefore this study proposed to examine the influence of coping strategies and perceived social stigmatization on psychological wellbeing of the spouses of male prisoners in Ibadan. Following from the arguments and review of literature above, the following hypotheses were derived: (1). Spouses of male prisoners with lower level of perceived social stigmatization will report significantly higher level of psychological wellbeing than partners with higher level of perceived social stigmatization (2). Emotion focused and problem focused coping will have significant joint and independent influence on psychological wellbeing (3). There will be a significant main and interaction influence of coping strategies and perceived social stigmatization on reported psychological wellbeing of spouses of male prisoners in Ibadan. 


\section{MATERIALS AND METHODS}

\subsection{Research Design}

A survey research using expo facto design was used for this study. This was chosen because there was no manipulation of any variable in the study, the study was "after fact" in nature as the variables already existed among the participants. Coping strategies and perceived social stigmatization were the independent variables of the study, while psychological wellbeing was the dependent variable. All variables were continuously and intervally measured hence the quantitative analyses adopted throughout the study.

\subsection{The Setting}

Ibadan, the capital city of Oyo state, is an urban city located in the humid Southwest of Nigeria. it is on a major route to the northern parts of Nigeria and is the largest of contemporary traditional towns (Ojedokun and Balogun, 2011). Ibadan is composed of the main city and its surburbs. Its main city alone, according to 2006 census results has 1,338,659 inhabitants (about 24.34\% of the entire state population). Administratively, Ibadan metropolis used to be under one local government, Ibadan Municipal Government, before it was split into five distinct local government areas, because of its largeness in terms of population and land mass. Ibadan is also where the seat of Government is. In spite of the high density nature of Ibadan (Ibadan is reputed to be the largest city south of the Sahara, or the third largest city in the whole of Africa), there is only one minimum security prison, located at Agodi area of the town, which is a walking distance from the government residential house, a legacy of the colonial administration of the past. Because of "security risk", the administrator of the prison refused to give details on the prison, but offered that there were male and female sections, with other relaxation facilities within the prison walls. However, the prison was said to be over congested (but no figure was given). The prison equally was located within Agodi gate market, in other words, it is surrounded by a market where different wares were sold on a daily basis.

\subsection{Participants}

Using purposive sampling technique (the study was only interested in the spouses of incarcerated male prisoners), one hundred and nine (109) female partners of prisoners in Ibadan, Nigeria who were visiting their partners participated in the study. They were female partners of both convicted and inmates awaiting trial. The inclusion criteria were participants who had to be willing to participate, who came to visit their partners and who were available throughout the duration of the study. $74(67.9 \%)$ of the participants were Christians and $35(32.1 \%)$ were Muslims. Their age ranged from 20 years to 65 years with mean age of 39.47 years and standard deviation of 10.03 years. $33(30.3 \%)$ of the participants had primary education, 43(39.4\%) had secondary education, 9 (8.3\%) had B.Sc, 17 (15.6\%) had M.Sc and 7 (6.4\%) had no formal education. In terms of their ethnicity, $12(11.0 \%)$ of the participants were Ibo, $93(85.3 \%)$ were Yorubas and $4(3.7 \%)$ were Hausas. Considering the level of their income, $64(58.8 \%)$ were low income earners, $40(36.7 \%)$ were medium income earners while $5(4.6 \%)$ were high income earners. $90(82.6 \%)$ of the participants were into business and 19 $(17.4 \%)$ were civil servants. $71(65.1 \%)$ had "good" health status, $32(29.4 \%)$ had "better" health status, 1 $(0.9 \%)$ had "worse" health status while $5(4.6 \%)$ had others. The length of sentence of participant's partners ranged from 1-19 months to above 46 months. Looking at the family type of the participants, $88(80.7 \%)$ were from monogamous families, while $21(19.3 \%)$ were from polygamous families. $80(73.4 \%)$ of the participants lived in a rented apartment, while 29 (26.6\%) lived in owned apartments. 40 (36.7) of the participants had husbands who were convicted of their crime, while 69 (63.3) had husbands who were awaiting trial.

\subsection{Research Instruments}

A well-structured questionnaire in four sections (A, B, C and D) was used to collect relevant data for this study.

Section A measured demographic characteristics of the prisoners female partners including age, religion, educational background, income, occupation, length of sentence of husband, health status, family type, ownership of house and type of crime.

Section B measured psychological wellbeing using a 22-item index developed by Goldberg (1988) and revised by Revicki et al. (1996). It has six sub-scales, namely: Anxiety, depressed mood, positive-wellbeing, selfcontrol, general health and vitality. It utilized a Likert format scale with 5 response options ranging from $1=$ none of the time to $5=$ all of the time. The author reported the following alpha levels for each subscale: Anxiety (0.82), depressed mood (0.89), positive wellbeing (0.88), selfcontrol (0.76), general health (0.61) and vitality (0.85). The higher the score, the better the level of perceived psychological wellbeing and vice versa.

Section C was the 9-item Social stigmatization scale, developed by Bada (2012). It has summated rating format with response choices ranging from $1=$ strongly 
disagree to $5=$ strongly agree. Bada reported an alpha coefficient of 90 . High score on the scale means high stigmatization, while low score means low stigmatization.

Section D contained a 28-item coping scale developed by Carver et al. (1989). It has summated rating with 4 response choices ranging from $1=$ usually don't do this at all to $4=$ usually do this. The author reported a reliability co-efficient of 0.82 for the scale. The scale was revalidated for this study and reported a Cronbach alpha of 0.75 and Guttman split reliability of 0.79. It was dichotomised into problem-focused coping and emotion-focused coping (Ben-Zur, 2005). The problem-focused coping strategy scale contains 15 items. The minimum score on this scale is 15 , while the highest is 60. On the other hand, the emotion-focused part contains 13 items with a minimum score of 13 and a maximum of 52. The higher the score on each of these subscales, the more the individual uses that method in any particular context/situation.

\subsection{Procedure}

The administration of the questionnaire took place at Agodi Prison in Ibadan, where the participants were purposively drawn from the partners who come around for visitation. Permission was sought from the controller of prisons by the researchers before the administration of the questionnaires. The verbal consent of prospective participants was sought after brief explanation of the research. Those who consented were given the questionnaire with assurance of anonymity and confidentiality of responses. Participants were also informed that they were not under any obligation to participate and that they had the right to withdraw at any point they felt inclined to discontinue with the exercise. It was impressed on the participants that there were no right or wrong answers but that they were encouraged to be honest in their responses.

\subsection{Data Analysis}

A $2 \times 2 \times 2$ ANOVA and t-test was utilised to analyze the data. Psychological wellbeing was regressed on coping strategies and perceived social stigmatization.

\section{RESULTS}

Table 1 shows that perceived social stigmatization has significant influence on psychological wellbeing among partners of prisoners $(\mathrm{t}=3.65$; $\mathrm{df}=107$; $\mathrm{p}<0.05)$. This means that participants with low perceived social stigmatization $(x=72.76 ; \mathrm{SD}=10.68)$ reported higher psychological wellbeing than those with high perceived social stigmatization $(x=66.39 ; \mathrm{SD}=7.37)$.

The result in Table 2 shows that there was no significant main effect of coping strategies (emotionfocused and problem-focused $)(F(1,101)=0.03$; $\mathrm{p}>0.05),(\mathrm{F}(1,101)=2.94 ; \mathrm{p}>0.05)$ and perceived social stigmatization $(F(1,101)=0.31 ; p>0.05)$ on psychological wellbeing. This means that the predictor variables did not independently predict psychological wellbeing among female partners of prisoners. However, there was an interaction effect of emotion focused coping and problem-focused coping on psychological wellbeing $(\mathrm{F}(1,101)=3.77 ; \mathrm{p}<0.05)$, meaning that the coping strategies used in the study jointly predicted psychological wellbeing among partners of prisoners, but there was no interaction of emotion-focused coping/perceived social stigmatization and problem focused/perceived social stigmatization on psychological wellbeing $(\mathrm{F}(1,101)=2.25 ; \mathrm{p}>0.05),(\mathrm{F}$ $(1,101)=3.30 ; p>0.05)$ respectively.

Finally, there was a joint interaction effect of emotion-focused coping, problem-focused coping and perceived social stigmatization on psychological wellbeing of the participants $(F(1,101)=13.50$; $\mathrm{p}<0.001)$. This means that the predictor variables jointly predict psychological wellbeing among female partners of prisoners. Based on these results, the hypothesis which stated that there would be a significant interaction effect of coping strategies (emotion-focused coping and problem-focused coping) and perceived social stigmatization on psychological wellbeing among the female partners of prisoners was confirmed.

The interaction influence of coping strategies and perceived social stigmatization are presented in Fig. 1 and 2 below.

Figure 1 shows the interaction influence of the variables on reported psychological wellbeing of the respondents where those who scored low on perceived social stigmatization and scored low on using problem-focused coping strategy reported higher psychological wellbeing than those who scored low on perceived stigmatization but scored high on using problem-focused coping strategy. On the other hand, those who scored high on perceived social stigmatization but scored low on using problemfocused coping strategy, reported lower psychological wellbeing as compared to those who scored high on perceived social stigmatization but reported using high problem-focused coping strategy. 
Bada Bukola Victoria et al. / Journal of Social Sciences 10 (1): 15-25, 2014

Table 1. Summary of independent t-test comparing level of perceived social stigmatization of partners of prisoners on psychological wellbeing

\begin{tabular}{llllrlll}
\hline & Perceived social stigmatization & $\mathrm{N}$ & Mean & SD & t & Df & P \\
\hline Psychological well being & Low & 38 & 72.76 & 10.68 & 3.65 & 107 & $<0.05$ \\
& HIGH & 71 & 66.39 & 7.37 & & & \\
\hline
\end{tabular}

Table 2. Summary of $2 \times 2 \times 2$ ANOVA showing the effect of coping strategies and perceived social stigmatization on psychological well being among female partners of prisoners

\begin{tabular}{lcllll}
\hline Source & Sum of squares & df & Mean square & F & P. \\
\hline Intercept & 104.05700 & 1 & 104.057 & 559.50 & $<0.001$ \\
Ee & 0.00600 & 1 & 0.00600 & 0.0300 & $>0.050$ \\
Pp & 0.54800 & 1 & 0.54800 & 2.9450 & $>0.050$ \\
Pss & 0.05800 & 1 & 0.05800 & 0.3130 & $>0.050$ \\
ee*pp & 0.70300 & 1 & 0.70300 & 3.7780 & $<0.050$ \\
ee*pss & 0.42000 & 1 & 0.42000 & 2.2560 & $>0.050$ \\
pp*pss & 0.61500 & 1 & 0.61500 & 3.3060 & $>0.050$ \\
ee*pp*pss & 2.51200 & 1 & 2.51200 & 13.508 & $<0.001$ \\
Error & 18.78400 & 101 & 0.18600 & & \\
\hline
\end{tabular}

a. $\mathrm{R}$ squared $=0.293$ (Adjusted $\mathrm{R}$ squared $=0.245$ )

KEY: ee-emotion-focused coping

pp- problem-focused coping

pss- perceived social stigmatization

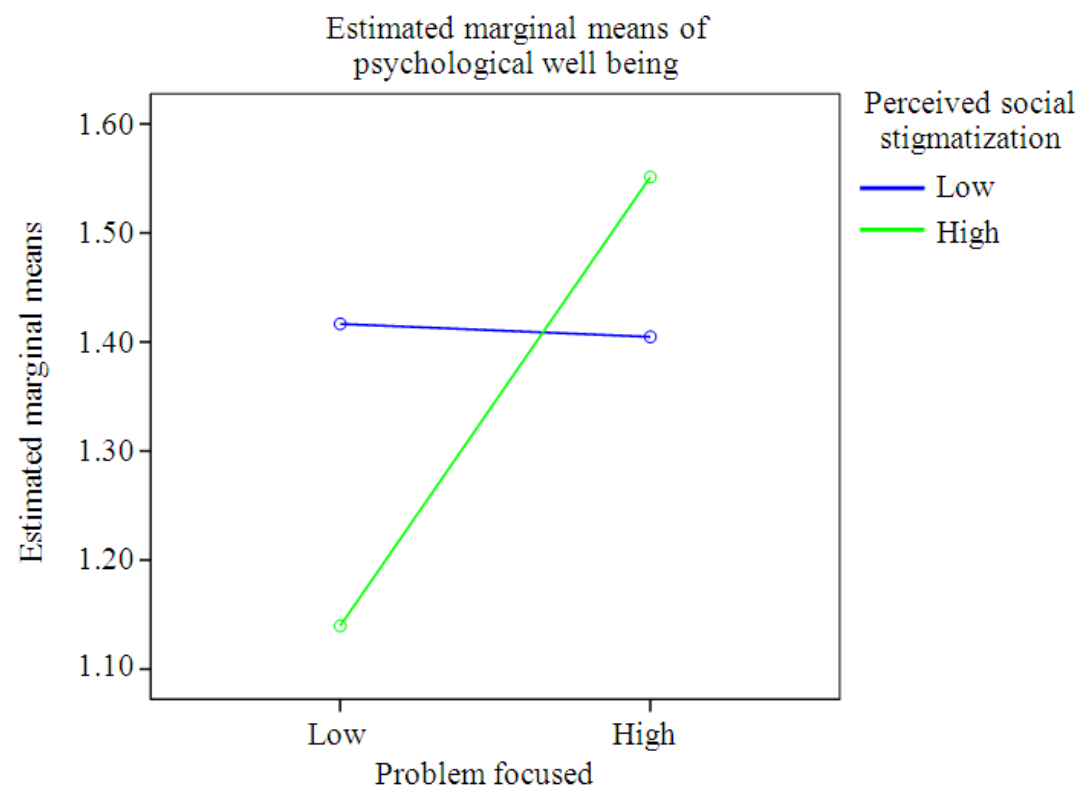

Fig. 1. Line graph representation of the interactive effect of problem-focused coping and perceived social stigmatization of respondents on reported psychological wellbeing

From Fig. 2 above, those who reported perceived low social stigmatization and scored low on using emotion-focused coping strategy, reported low psychological wellbeing than those who scored low on perceived social stigmatization but scored high on using emotion focused coping strategy. On the other hand, those who scored high on perceived social stigmatization but scored low on using emotionfocused coping strategy, reported higher psychological wellbeing as compared to those who scored high on perceived stigmatization and scored high on using emotion-focused coping strategy. 


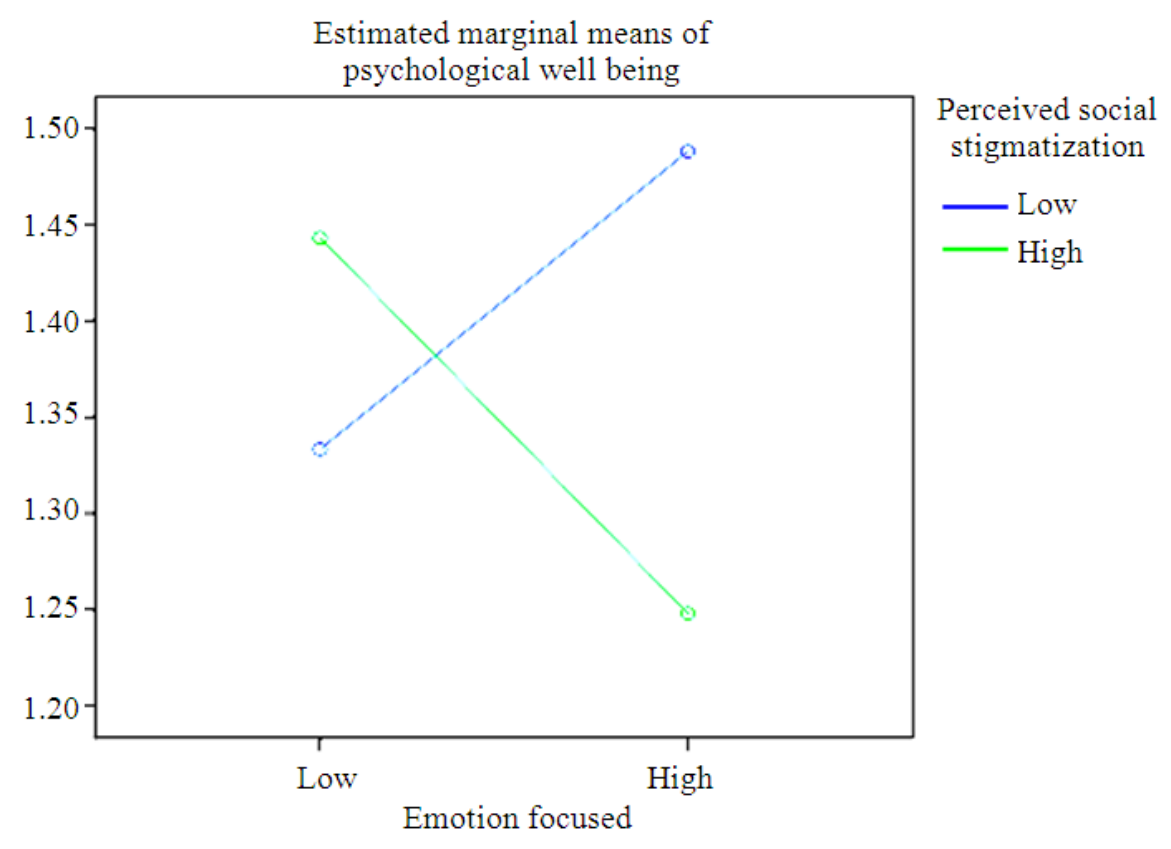

Fig. 2. Line graph representation of the interactive effect of emotion-focused coping and perceived social stigmatization of respondents on reported psychological wellbeing

\section{DISCUSSION}

The hypothesis which stated that spouses of male prisoners with lower levels of perceived social stigmatization will report significantly higher level of psychological wellbeing than spouses with higher level of perceived social stigmatization was supported. This means that the spouses of male prisoners reported a higher level of perceived psychological wellbeing when they perceived that they had lower level of social stigma, meaning that the lower the perceived stigmatization, the higher their reported psychological wellbeing. This finding corroborates the study of Major and O'Brien (2005), which found that many people who have been stigmatized feel as if they are transforming from a whole person to a tainted one; they feel different and devalued by others. In the present study, the less the female partners perceived that they are being stigmatized, the more they have (or perceived) meaningful psychological wellbeing, probably perceiving that there is positive social support and acceptance by the society (Bada et al., 2014). Stigma may affect the behaviour and psychological wellbeing of those who are stigmatized, as this may be a source of concern and a stressor to them. Social stigma put a person's social identity under threat, such as through low self-esteem and poor psychological wellbeing. The implication of this is that people, perhaps especially significant others, would help spouses of incarcerated individuals cope well with the situation if the spouses are less stigmatized.

It is expected that if there is a lower level of stigmatization, the female partners would be able to cope well with the confronting reality of their spouses being incarcerated. In the present study, coping strategies (emotion-focused coping and problem-focused coping) independently did not predict psychological wellbeing. This is contrary to the findings of Bada et al. (2013), which reported that coping strategies had influence on the psychological wellbeing of female partners of prisoners, particularly the problem-solving strategy, because the spouses' conditions were put into perspective and proper context. The concern of the spouses was like "now that my husband/partner is incarcerated for a particular period of time, how do I cope with possible outcomes of this for myself and the rest of the family members left behind". With that disposition, they were probably able to adjust better to the reality of missing the "breadwinner" for a period of time. Whenever the correct coping mechanism is used, it will help in restoring balance in their lives. Coping strategies, especially problem-focused coping, will help the female partners of prisoners to confront the reality 
that they are responsible for their own state of good and balanced psychological wellbeing.

Contrary to the present finding, Ben-Zur (2005) found that emotion-focused strategies showed substantial positive association with distress and poor wellbeing than problem-focused strategies. It is also noted that problem-solving and emotion-focused coping are the terms used by Compas (1987) and Lazarus and Folkman (1984), who found problem-solving to be utilized in order to change situations, while altering situations themselves elicit emotion-focused coping. This result showed that coping strategies (problem-focused and emotion-focused coping) has no significant independent contribution to psychological wellbeing. It also indicated that social stigmatization independently did not predict psychological wellbeing. From the study, this means that female partners of prisoners have not allowed the reaction of others to affect the outcome of their wellbeing. When stigma is not well managed, it will result in poor psychological wellbeing for the individuals experiencing it. This is contrary to the findings of Hannem (2003), who reported that research on stigmatization reveals that individuals are conscious of their discredited status and wellbeing and that stigma may affect the behaviour and psychological wellbeing of those who are stigmatized (Major and O'Brien, 2005).

In contrast, a combined influence of coping strategies and perceived social stigmatization on psychological wellbeing among female partners of prisoners was fully confirmed. Considering the interaction between perceived stigmatization and coping strategies, if the female partners are stigmatized but make use of a problem-focused coping strategy, it will help to improve or increase psychological wellbeing; in a case whereby they are stigmatized and make use of emotion-focused coping, there is every likelihood that they have poor psychological wellbeing. Figure 1 shows the interaction influence of the variables on perceived psychological wellbeing of the participants. Spouses who scored low on perceived social stigmatization and scored low on using problem-focused coping strategy reported high psychological wellbeing than those who though scored low on social stigmatization but scored high on using problem-focused coping strategy. This could be due to their concern (the latter group) about the challenges they may likely be facing at the home front and coping with such challenges. On the other hand, those who scored high on social stigmatization but scored low on using problem-focused coping strategy reported low psychological wellbeing as compared to those who scored high on social stigmatization and also scored high on using problem-focused coping strategy, probably due to their ability to situate things within the proper context in which they occur. For example, it is possible the situation is being perceived as "It is has happened and there is nothing they can do about it and therefore decided to confront the situation "as is"“".

With emotion-focused coping strategy, those who scored low social stigmatization and also scored low on using emotion-focused coping strategy reported low psychological wellbeing compared to those who scored low on social stigmatization but reported using high emotion-focused coping strategy. The former show a healthier adjustment to the situation at hand, while the latter could be seriously emotionally disturbed. On the other hand, those who scored high on social stigmatization but low on use of emotion-focused coping strategy reported high psychological wellbeing as compared to those who scored high on social stigmatization and high on using emotion-focused coping strategy. This is expected in that the stigmatization is disturbing in itself and may consequently have effects on their emotions, hence the low psychological wellbeing reported.

[need a straightforward, jargon-free summary of the findings to conclude this section].

\subsection{Implications and Recommendations}

The major objective of this study was to examine coping strategies and perceived social stigmatization as predictors of psychological wellbeing. The use of coping strategies in the face of social stigmatization has great implications for the psychological wellbeing of female partners of male prisoners. If the partners are able to contextualise the problem at hand, even if they experience high level of social stigmatization, they may be able to wade through the impact of incarceration of the husbands and consequently experience good psychological wellbeing. It is recommended that government at all levels, NGOs, private organizations, philanthropists in the country, faith groups and communities should explore means of eliminating social stigmatization of prisoners and their significant others. In so doing, the psychological health (wellbeing) of these significant others and probably the prisoners as well, would not be adversely affected and so would be able to impact positively on society in the long run. Meanwhile, female partners of prisoners need to make use of coping strategies that will contribute positively to their psychological wellbeing through proper psychoeducation by professionals.

\subsection{Limitations}

As typical of research work, the present study is not without limitations. In the first instance, the study 
considered only female partners of prisoners sampled in Agodi prison Ibadan, so male partners of prisoners are left out of the study. There may be issues that are specific to partners of females prisoners that may bring about differences in outcomes.

Another limitation was financial constraint as well as time that made it impossible to conduct a cross-cultural study that could have provided more comprehensive research findings among the female partners of prisoners. This type of research is better done with a research grant, which can give room for the research setting to be broadened and give more strength to the findings and generalisation of the results. The general attitude of people towards responding to research instrument (i.e., questionnaire) is a serious limitation that the researchers experienced in the field.

Lastly, we could not make causal attribution in the present study as to what caused one variable to influence the other because of the study design. The findings could be enhanced further if a causal approach was adopted so that we can say one variable caused the other to behave the way it did.3

\subsection{Suggestions for Future Studies}

For a wider generalisation of the findings, future researchers in this area of study could usefully consider an enlargement of the study setting in order to have a broader national and international outlook as well as to make generalisation possible.

This present study was purposive in that it sampled only female partners of prisoners. It is therefore suggested that future research should accommodate both male and female partners to enhance generalization and comparison based on sex differences.

\section{CONCLUSION}

In spite of the obvious limitations, it can be reasonably concluded that if there is social stigmatisation of the relatives (especially spouses) of incarcerated men and appropriate coping mechanism is adopted, then the wellbeing of the relatives would be at acceptable level to effectively function in the society.

\section{REFERENCES}

Adegoke, S., 2011. Family burden in incarceration: Implication for services. Soc. Psychol. Epidem., 28: 207-210.
Angermeyer, M.C. and S. Dietrich, 2006. Public beliefs about and attitudes towards people with mental illness: A review of population studies. Acta Psychol. Scand., 113: 163-179. DOI: 10.1111/j.1600-0447.2005.00699.x

Aspinwall, L.G. and S. Taylor, 1997. A stitch in time: Self-regulation and proactive coping. Psychol. Bul., 121: 417-436. DOI: 10.1037/00332909.121.3.417

Atere, M.I., 2000. Dialogue as a Solution to Religious Problems in Nigeria. In: Social Problems and Social Work in Nigeria, Odumosu, T., W. Atere and F. Adewunmi (Eds.), Centre for Planning Studies, Lagos State University, Lagos.

Aungles, A., 1994. The Prison and the Home: A Study of the Relationship between Domesticity and Penality. 1st Edn., Institute of Criminology, University of Sydney Law School, Sydney, SBN-10: 0867589035, pp: 302.

Bada, B.V., 2012. Social support, perceived social stigmatization, coping strategies and emotional needs as predictor of psychological well-being among female partners of prisoners in Ibadan and the effectiveness of psycho-education. PhD Thesis, University of Ibadan, Nigeria.

Bada, B.V., S.K. Balogun and G.A. Adejuwon, 2013. Psychological factors predicting psychological wellbeing among spouses of male prisoners in Ibadan, Nigeria. Health Care, 1: 76-82. DOI: 10.12966/hc.11.06.2013,

Bada, V.O., S.K. Balogun and G.A. Adejuwon, 2014. Social support, religion and education as predictors of psychological well-being among female partners of prisoners in Ibadan. Brit. J. Educ., Soc. Behav. Sci., 4: 156-166.

Ben-Zur, H., 2005. Coping, distress and life events in a community sample. Inter. J. Str. Manage., 1: 188196. DOI: $10.1037 / 1072-5245.12 .2 .188$

Blaine, G.B., 2010. The college therapist's responsibility to the student, the university and the parents. Am. J. Orthopysch., 34: 481-485. DOI: 10.1111/j.19390025.1964.tb02216.x

Cairns, E. and R. Wilson, 1989. Coping with political violence in Northern Ireland. Soc. Sci. Med., 28: 621-624. DOI: 10.1016/0277-9536(89)90257-8

Campbell, A., 1976. Subjective measures of well-being. Am. Psychol., 31: 117-124. DOI: 10.1037/0003066X.31.2.117 
Cantos, A.L., P.H. Neidig and K.D. O’Leary, 1993. Men's and women's attributions of blame for domestic violence. J. Fam. Viol., 8: 289-302. DOI: 10.1007/BF00978094

Carlson, B. and N. Cervera, 1992. Inmates and their female partners: Incarceration and family life. Westport Greenwood Publishing Group.

Carver, C.S., M.F. Scheir and J.K. Weintraub, 1989. Assessing coping strategies: A theoretical based approach. J. Pers. Soc. Psychol., 56: 267-283. DOI: 10.1037/0022-3514.56.2.267

Claerhout, S., J. Elder and C. Janes, 1982. Problemsolving skills for rural battered women. Am. J. Commun. Psychol. 10: 605-612. DOI: 10.1007/BF00894147

Compas, B.E., 1987. Coping with stress during childhood and adolescence. Psychol. Bul., 101: 393403. DOI: 10.1037/0033-2909.101.3.393

Conway, V.J. and D.J. Terry, 1992. Appraised controllability as a moderator of the effectiveness of different coping strategies: A test of the goodness of fit hypothesis. Aust. J. Psychol., 44: 1-7. DOI: 10.1080/00049539208260155

Cooper, C.L. and B. Payne, 1991. Personality and Stress: Individual Differences in the Stress Process. 1st Edn., Wiley, New York.

Corrigan, P.W. and A.K. Matthews, 2003. Stigma and disclosure: Implications for coming out of the closet. J. Men. Health, 12: 235-248. DOI: $10.1080 / 0963823031000118221$

Crisp, A.H., M.G. Gelder, S. Rix, H.I. Meltzer and O.J. Rowland, 2000. Stigmatisation of people with mental illness. Brit. J. Psychol., 177: 4-7. DOI: 10.1192/bjp.177.1.4

Diener, E., M. Diener and C. Diener, 1995. Factors predicting the subjective well-being of nations. J. Pers. Soc. Psychol., 69: 851-864. DOI: 10.1037/0022-3514.69.1.120

Folkman, S. and R.S. Lazarus, 1980. An analysis of coping in a middle aged community Sample. J. Health Soc. Behav., 21: 219-239. DOI: 10.2307/2136617

Folkman, S., R.S. Lazarus, C. Dunkel-Shetteer, A. DeLongis and R. Gruen, 1986a. Dynamics of a stressful encounter: Cognitive appraisal, coping and encounter outcomes. J. Pers. Soc. Psychol., 50: 9921003. DOI: $10.1037 / 0022-3514.50 .5 .992$

Folkman, S., R.S. Lazarus, R.J. Gruen and A. DeLongis, 1986b. Appraisal, coping, health status and psychological symptoms. J. Pers. Soc. Psychol., 50: 571-579. DOI: 10.1037/0022-3514.50.3.571
Goldberg, D.P., 1988. The Users' Guide to the GENERAL Health Questionnaire. 1st Edn., NFERNelson, Windsor, pp: 129.

Goldberg, L. and S. Breznitz, 1982. Handbook of Stress: Theoretical and Clinical Aspects. 1st Edn., Free Press, New York, ISBN-10: 0029119502. pp: 804

Grinstead, O., B. Faigeles, C. Bancroft and B. Zack, 2001. The financial cost of maintaining relationships with incarcerated African American men: A survey of women prison visitors. J. Afr. Am. Men, 6: 59-69. DOI: $10.1007 / \mathrm{s} 12111-001-1014-2$

Hannem, S., 2003. Marked by association: Stigma, marginalization, gender and the families of male prisoners in Canada. PhD Thesis, University of Ottawa, Ottawa.

Kamya, H.A., 2000. Hardiness and Spiritual wellbeing among social work students: implication for social work education. J. Soc. Work Educ., 36: 231-240.

Launius, M.H. and B.L. Jensen, 1987. Inter-personal problem-solving skills in battere, counseling and control women. J. Fam. Viol., 2: 151-162. DOI: 10.1007/BF00977039

Lazarus, R.S., 1993. Coping theory and research: Past, Present and future. Psychosom. Med., 55: 234-247.

Lazarus, S.K. and J.K. Folkman, 1984. Determinants of condom use to prevent HIV infection among youth in Ghana. J. Adolesc. Health, 24 63-72.

Major, B. and L.T. O'Brien, 2005. The social psychology of stigma. Ann. Rev. Psychol., 56: 393- 421. DOI: 10.1146/annurev.psych.56.091103.070137

Miller, D.T. and C.A. Porter, 1983. Selfblame in victims of violence. J. Soc. Iss., 39: 139-152.

Odekunle, F., 1976. Capitalist Economy the Crime Problem in Nigeria. Proceedings of the Conference Inequality and Social Differentiation in Africa, (SDA' 76), New York.

Oevrholser, J.C. and S.H. Moll, 1990. Who is to blame: Attributions regarding causality in spouse abuse. Behav. Sci. Law, 8: 107-120.

Ojedokun, O. and S.K. Balogun, 2011. Responsible environmental behaviour among residents of Ibadan: where is the place of attitude towards littering in the agenda to keep Ibadan clean? Ibad. Plan J., 1: 67-81.

Perlin, L.I and C. Schooler, 1978. The structure of coping. J. Health Soc. Behav., 19: 2-21. DOI: $10.2307 / 2136319$

Revicki, D.A., N.K. Leidy and L. Howland, 1996. Evaluating the psychometric characteristics of the psychological General wellbeing index with a new response scale. Qual. Life Res., 5: 419-425. DOI: 10.1007/BF00449916 
Taylor, S.E., M.E. Kemeny, E.M. Reed, J.E. Bower and T.E. Gruenewald, 2000. Psychological resources, positive illusions and health. Am. Psychol., 55: 99-109. DOI: 10.1037/0003066X.55.1.99

Vitaliano, P.P., D.J. DeWolfe, R.D. Mauiro, J. Russo and W. Katon, 1990. Appraised changeability of a stressor as a modifier of the relationship between coping and psychological distress: A test of the hypothesis of fit. J. Pers. Soc. Psychol., 59: 582592. DOI: 10.1037/0022-3514.59.3.582
Vogel, D.L, N.G. Wade and S. Haake, 2006. Measuring the self stigma associated with seeking psychological help. J. Counsel. Psychol., 53: 325337. DOI: $10.1037 / 0022-0167.53 .3 .325$

Whatley, SL., A.C. Foreman and S. Richards, 1998. The relationship of coping style to dysphoria anxiety and anger. Psychol. Rep., 83: 783-791. DOI: 10.2466/pr0.1998.83.3.783

Wolf, C.T. and P. Stevens, 2001. Integrating religion and spirituality in marriage and family counseling. Counseling Values, 46: 66-75. DOI: 10.1002/j.2161007X.2001.tb00207.x 